\title{
Height and weight achievement in cleft lip and palate
}

Jane Lee, June Nunn, Charlotte Wright

This paper was originally published last October (1996; 75:327-329). It is being republished as tables $2-5$ were inadvertently omitted.
Northumberland Community Health NHS Trust, Morpeth J Lee

Department of Child Dental Health, Newcastle University, Newcastle

J Nunn

Department of Child Health, Newcastle University, Newcastle C Wright

Correspondence to: Dr Charlotte Wright, First Assistant in Community Child Health, Donald Court House, 13 Walker Terrace, Gateshead NE8 3EB.

Accepted 19 July 1996

\begin{abstract}
Growth was studied in 83 children with cleft lip and/or palate aged 0-4 years attending a specialist regional centre. Information was collected by a personal interview, postal questionnaire, and record review. The group as a whole grew relatively poorly in early infancy but subsequently recovered, attaining both expected weight and height by last follow up at age 25.5 months (range 3 to 47). However, the group proved heterogeneous, with children with isolated clefts of the secondary palate showing the most abnormal growth. Children with underlying syndromes were significantly more likely to be short at follow up, while type or severity of cleft was not significantly related to follow up height. Therefore, while cleft palate was associated with significant growth faltering in early infancy, rapid recovery took place following surgical repair and appears to have resulted in no residual growth deficit. (Arch Dis Child 1997;76:70-72)
\end{abstract}

Keywords: cleft palate; failure to thrive; growth.

The anatomical defects suffered by children with cleft lip and palate are a known cause of early difficulties with feeding which can lead to undernutrition and compromised growth. It is well documented that in the early months after birth, children with clefts fail to achieve satisfactory growth. ${ }^{12}$ However, it is not clear whether growth patterns return to normal after surgery. It is also not clear whether any observed short stature in children with cleft lip and palate is a result of early undernutrition or to stunting due to an underlying syndrome. In this study we explored the relative influence of cleft type and the experience of early feeding problems on weight and height gain during and after corrective surgery.

\section{Methods}

SUBJECTS

A cohort of cleft lip and/or cleft palate children who attended the outpatient cleft palate clinic at the Royal Victoria Infirmary, Newcastle upon Tyne, were studied. This clinic cares for patients from a wide geographical area, extending from the River Tyne north to the border with Scotland, west to include Cumbria, and east to include North Tyneside. In addition, there are occasional referrals from other neighbouring districts. We identified all children who had been registered with this service for the previous four years who were aged 0-4 years at the time of study and had been born at or beyond 37 weeks' gestation.

For the purposes of this study the various types of cleft lip and palate were grouped into three categories, based on anatomical boundaries: the 'lip' group comprised those with clefts of the primary palate (lip and/or alveolus) only, the 'palate' group comprised those with clefts of the secondary (hard or soft) palate only, and the 'combined' group comprised those with clefts of primary and secondary palates occurring together.

\section{PROCEDURES}

The study took place over a six month period, and data were collected from three sources.

(1) The parents of those children who attended the outpatient clinic during the study period were invited to take part in a structured interview to collect background data and information about feeding. Direct measurements of height and weight of the child and height of parents (in order to calculate mid-parental height predictions) were also undertaken by a trained technician using electronic scales and a stadiometer and reported heights were obtained for absent parents.

(2) Postal questionnaires were sent to the parents of those children not due for recall during the study period as well as those who failed to attend their appointments during the study period. The questionnaire incorporated all the items asked at the structured interview and requested that the parents also fill in an up to date weight measurement for the child and reported parental heights.

(3) The medical notes were reviewed in all cases to retrieve details of hospital admissions and diagnosis.

\section{ANALYSIS}

The growth data were entered into the Castlemead growth program ${ }^{3}$ in order to transform them into standard deviation scores (SDS) compared to the new United Kingdom national standard. ${ }^{4}$ Growth data were only used for infants born after 36 weeks, as reliable preterm standards were not available. In addition the growth package calculated a target adult height from parental heights ${ }^{5}$ and this was also converted into SDS. The questionnaire and interview results were entered into a separate database and then combined with the growth data for analysis in Epi-Info. ${ }^{6}$

To provide a measure of weight gain over time, the thrive index was used. ${ }^{7}$ This com- 
Table 1 Prevalence of associated syndromes, by cleft type

\begin{tabular}{|c|c|c|c|c|c|c|c|c|}
\hline & \multicolumn{2}{|l|}{ Lip } & \multicolumn{2}{|c|}{ Palate } & \multicolumn{2}{|c|}{ Combined } & \multirow{2}{*}{ Total } & \multirow{2}{*}{$p\left(\chi^{2}\right)$} \\
\hline & No & $\%$ & No & $\%$ & No & $\%$ & & \\
\hline Syndrome & 1 & 4.3 & 10 & 29.4 & 3 & 11.5 & 14 & 0.03 \\
\hline Total & 23 & & 34 & & 26 & & 83 & \\
\hline
\end{tabular}

pares a child's attained weight SDS to that predicted by their early weight measurements, incorporating a constant to correct for regression to the mean - the tendency for very large or small children to converge towards average. The thrive index (TI) is thus defined as:

$\mathrm{TI}=$ current weight SDS - baseline weight SDS $\times$ constant.

For this study, since children were likely to have feeding difficulties from birth onwards, the only suitable baseline measurement was that of birthweight. However, there are high levels of variation in the early weeks after birth so that correction for regression to the mean is essential. From further analyses of the large population data set from which the thrive index was derived, we have calculated the regression coefficient between birth and a wide range of subsequent ages, and these coefficients were used as constants to adjust for regression to the mean in the formula above. For measurements recorded at the time of lip surgery (around 3 months) a constant of 0.64 was used; for measurements around the time of palate surgery at around 6 months, a constant of 0.44 was used; and for follow up at ages ranging from 1-4 years, a constant of 0.41 was used.

\section{Results}

Eighty three eligible children were identified, of whom 44 were seen in the outpatient clinic during the study period. Data were collected by postal return for 23 children and in 16 children information was restricted to what could be retrieved through the medical notes. Roughly one third of the children fell into each cleft typ$\mathrm{e}$ (table 1) and 14 (17\%) had associated syndromes (nine Pierre Robin; one each Van de Woude, Stickler, and De Grouchy; two unidentified). Children were followed up at a mean age of 25.5 months (range 3-47 months) and $58 \%$ of the children were male; $96 \%$ of the children were Caucasian.

Of the 67 families for whom interviews or questionnaires were completed, $55(82 \%)$ of children had been solely bottle fed, while the majority of the remainder received a mixture of breast and formula milk, with a minority receiving a high energy formula milk. There were seven types of bottle feeding equipment used, the most popular being the Rosti bottle, used by $92 \%$. Only two children had an orthodontic plate fitted.

Forty two children $(63 \%)$ were reported to have had feeding difficulties at some time. Children with isolated palate defects were significantly more likely to have had feeding problems than those with lip only or combined lip and palate defects (table 2). The most common types of difficulty identified by parents were nasal regurgitation and vomiting. The majority of these problems resolved after palate repair, but 12 children (29\%) were still reported to have feeding problems at follow up, two of whom had residual clefts. Thirty four parents $(51 \%)$ reported receiving dietary advice of some kind, but only four saw a dietician.

Weight measurements were only consistently available for children at four time points: at birth, on admission before lip surgery, on admission before palate surgery and at follow up. All the cleft types had near average weights at birth; those who had lip surgery had already shown a small fall, with a larger fall before palate surgery, but at follow up the weight SDS was again near to average. When these falls are expressed in the form of the thrive index (table 3 ), the differences between the cleft types are more manifest, with the palate group showing both the largest median falls preoperatively and having the poorest weight outcome at follow up. Similarly, a significantly higher proportion of the palate group manifested failure to thrive at some point, in that they fell into the slowest gaining $10 \%$ preoperatively, with a trend for this to persist at follow up (table 4). It would be expected that children with feeding problems would be more likely to grow poorly, and 24 of the children with feeding problems $(57 \%)$ did fall into the slowest gaining $10 \%$, compared to only nine $(36 \%)$ of those without, but this difference was not significant $(p=0.21)$.

When examining the height outcome, there was also a strong relation with cleft type, with palate group having lower mean height SDS at follow up than the other groups. However, since this group also included a much higher proportion of children with syndromes, the effect of this on weight gain and height outcome was also examined. This showed that children with syndromes did have significantly poorer weight and height growth. When the independent effect of cleft type was assessed within the syndrome and non-syndrome groups, it was still significantly associated with weight outcome, but not height (table 5). Neither cleft type nor the presence of a syndrome was associated with any systematic difference in mid-parental heights.

\section{Discussion}

This study shows that while all children with clefts have a tendency to early growth faltering, there are subgroups with more compromised growth. The complex nature of the growth process, coupled with the specific feeding difficulties encountered by cleft lip and palate children, can make it difficult to disentangle the different influences and decide how great a part each factor has played in the eventual outcome. It would appear, however, that the type of cleft defect has greatest influence on the severity of failure to thrive, a view shared by more than one previous investigator. ${ }^{8}{ }^{9}$ Those children $^{2}$ with cleft of primary palate alone do not seem to show a significant degree of compromised growth, while the children with isolated clefts of the secondary palate, growth fell away substantially before palate surgery. However, the average fall made by even the most severely 
Table 2 Prevalence of feeding problems, by cleft type

\begin{tabular}{|c|c|c|c|c|c|c|c|c|}
\hline \multirow{2}{*}{ Feeding problems } & \multicolumn{2}{|c|}{ Lip } & \multicolumn{2}{|c|}{ Palate } & \multicolumn{2}{|c|}{ Combined } & \multirow{2}{*}{ Total } & \multirow{2}{*}{$p\left(\chi^{2}\right)$} \\
\hline & No & $\%$ & No & $\%$ & $\mathrm{No}$ & $\%$ & & \\
\hline Ever & 5 & 31.3 & 26 & 83.9 & 11 & 55.0 & 42 & 0.0014 \\
\hline Currently & 1 & 6.7 & 8 & 25.8 & 3 & 15.0 & 12 & 0.23 \\
\hline Total & 23 & & 34 & & 26 & & 83 & \\
\hline
\end{tabular}

Table 3 Median thrive index values at different stages, by cleft type

\begin{tabular}{|c|c|c|c|c|c|c|c|}
\hline \multirow{2}{*}{$\begin{array}{l}\text { Thrive } \\
\text { index at }\end{array}$} & \multicolumn{2}{|l|}{ Lip } & \multicolumn{2}{|l|}{ Palate } & \multicolumn{2}{|c|}{ Combined } & \multirow{2}{*}{$\begin{array}{l}p \\
\text { (Kruskal- } \\
\text { Wallis) }\end{array}$} \\
\hline & Median & $\begin{array}{l}\text { Interquartile } \\
\text { range }\end{array}$ & Median & $\begin{array}{l}\text { Interquartile } \\
\text { range }\end{array}$ & Median & $\begin{array}{l}\text { Interquartile } \\
\text { range }\end{array}$ & \\
\hline Lip surgery & -0.22 & $\begin{array}{l}-0.58 \text { to } \\
+0.48\end{array}$ & - & - & -0.26 & $\begin{array}{l}-0.89 \text { to } \\
+0.29\end{array}$ & 0.133 \\
\hline $\begin{array}{l}\text { Palate } \\
\text { surgery }\end{array}$ & - & - & -0.85 & $\begin{array}{l}-1.49 \text { to } \\
-0.49\end{array}$ & -0.28 & $\begin{array}{l}-0.96 \text { to } \\
+0.37\end{array}$ & 0.01 \\
\hline Follow up & +0.59 & $\begin{array}{l}-0.02 \text { to } \\
+1.01\end{array}$ & -0.20 & $\begin{array}{l}-0.93 \text { to } \\
+0.53\end{array}$ & -0.25 & $\begin{array}{l}-0.65 \text { to } \\
+1.19\end{array}$ & 0.001 \\
\hline
\end{tabular}

Table 4 Number of children with failure to thrive (FTT) at different stages, by cleft type

\begin{tabular}{|c|c|c|c|c|c|c|c|}
\hline \multirow{2}{*}{ FTT at } & \multicolumn{2}{|l|}{ Lip } & \multicolumn{2}{|c|}{ Palate } & \multicolumn{2}{|c|}{ Combined } & \multirow{2}{*}{$p\left(\chi^{2}\right)$} \\
\hline & No & $\%$ & No & $\%$ & No & $\%$ & \\
\hline Lip surgery & 5 & 21.7 & - & - & 7 & 26.9 & 0.67 \\
\hline Palate surgery & - & - & 15 & 44.1 & 5 & 19.2 & 0.043 \\
\hline Follow up & 2 & 8.7 & 5 & 14.7 & 2 & 7.7 & 0.64 \\
\hline
\end{tabular}

Table 5 Height and weight outcomes, by cleft type and the presence of an associated syndrome

\begin{tabular}{|c|c|c|c|c|c|c|c|}
\hline & \multicolumn{2}{|l|}{ Lip } & \multicolumn{2}{|l|}{ Palate } & \multicolumn{2}{|c|}{ Combined } & \multirow{2}{*}{$\begin{array}{l}\text { p } \\
\text { (Kruskal- } \\
\text { Wallis) }\end{array}$} \\
\hline & Median & $\begin{array}{l}\text { Interquartile } \\
\text { range }\end{array}$ & Median & $\begin{array}{l}\text { Interquartile } \\
\text { range }\end{array}$ & Median & $\begin{array}{l}\text { Interquartile } \\
\text { range }\end{array}$ & \\
\hline \multicolumn{8}{|l|}{ No syndrome } \\
\hline Weight SDS & 0.08 & $\begin{array}{l}-0.02 \text { to } \\
+0.81\end{array}$ & -0.3 & $\begin{array}{l}-0.81 \text { to } \\
+0.12\end{array}$ & -0.065 & $\begin{array}{l}-0.46 \text { to } \\
+1.24\end{array}$ & 0.044 \\
\hline Height SDS & 0.32 & $\begin{array}{l}-0.77 \text { to } \\
+1.15\end{array}$ & -0.28 & $\begin{array}{l}-1.19 \text { to } \\
+0.98\end{array}$ & 0.04 & $\begin{array}{l}-0.39 \text { to } \\
+1.65\end{array}$ & 0.78 \\
\hline $\begin{array}{l}\text { Number } \\
\text { Wt/Ht }\end{array}$ & $15 / 15$ & & $20 / 19$ & & $16 / 13$ & & \\
\hline \multicolumn{8}{|l|}{ Syndrome } \\
\hline Weight SDS & -1.98 & & -0.68 & $\begin{array}{l}-1.47 \text { to } \\
-0.04\end{array}$ & -0.55 & $\begin{array}{l}-0.38 \text { to } \\
+0.46\end{array}$ & 0.60 \\
\hline Height SDS & - & & -0.88 & $\begin{array}{l}-1.12 \text { to } \\
-0.88\end{array}$ & -0.61 & $\begin{array}{l}-2.97 \text { to } \\
-0.44\end{array}$ & 0.94 \\
\hline $\begin{array}{l}\text { Number } \\
\text { Wt/Ht }\end{array}$ & $1 / 0$ & & $8 / 7$ & & $3 / 3$ & & \\
\hline
\end{tabular}

affected group was only slightly more than the distance between two centile lines, and all cleft types showed catch up after surgery to centile positions close to those predicted for normal children, a finding that has been described in a previous study. ${ }^{10}$

It is not hard to explain the growth faltering seen, since a large proportion of the children in the study population experienced early feeding difficulties which were often prolonged and multiple. Considering the large number of feeding problems, it is of concern that half the parents said they had never received dietary advice and only $6 \%$ ever saw a dietician. In a group of children who have considerable potential for compromised growth, it would seem desirable that appropriate and timely dietary advice be given, possibly by involving a dietician in the interdisciplinary surgical team. Certainly the height and weight of cleft palate children should be routinely recorded when they attend the outpatient clinic to allow for prompt identification of a growth deficit, so that appropriate action can be taken. ${ }^{2}$

Although the numbers were small, the presence of a syndrome did appear to be important in predicting height achievement, an observation that has been made previously. ${ }^{9}$ However, in those children with syndromes who showed compromised growth, it is not clear whether this was a direct result of their clefts, a constitutional manifestation of their syndrome, or a result of endocrine insufficiency, which can be caused by hypothalamo-pituitary lesions associated with midline clefts, since children were not routinely screened for the latter.

In conclusion, we suggest that short term weight faltering is commonly seen in children with clefts of the secondary palate, particularly where this occurs in isolation, but that this is of a short term nature. Following reparative surgery, catch up is shown by children with all cleft types and there is no lasting effect on either weight or attained height. Where differences in stature are observed, it is likely that these are constitutional growth patterns related to an underlying syndrome. Although the weight faltering is a temporary phenomenon, it is likely to cause great anxiety to parents, who might benefit from a more proactive attempt to offer dietary advice and support in the early weeks of their child's life.

We are grateful to all the parents and children who participated in this study and to Miss CA Reid for giving generous clinical
access, to Mrs S Dodds for her help with data collection, and to Mr D Evans for his help with the initial analysis.

1 Avedian L, Ruberg R. Impaired weight gain in cleft palate infants. Cleft Palate f 1980;17:24-6.

2 Bowers E, Mayro R, Whitaker L. General body growth in children with clefts of the lip, palate and craniofacial strucchildren with clefts of the lip, palate and cranio
ture. Scand $\mathcal{F}$ Plast Reconstr Surg 1987;21:7-14.

3 Boyce L. Growth program versions I and II.Welwyn Garden City: Castlemead Publications, 1993.

4 Freeman JV, Cole TJ, Chinn S, Jones PRM, White EM, Preece MA. Cross sectional stature and weight reference curves for the UK, 1990. Arch Dis Child 1995;73:17-24.

5 Tanner JM, Goldstein H, Whitehouse RH. Standards for children's height at ages 2-9 years allowing for height of parents. Arch Dis Child 1970;45:755-62.

6 Dean J, Dean A, Burton A, Dicker R. Epi-Info. 5th Ed. Atlanta: Centers for Disease Control, 1990.

7 Wright CM, Waterston A, Matthews JNS, Aynsley-Green A. What is the normal rate of weight gain in infancy? Acta Paediatr 1994;83:351-6.

8 Jones W. Weight gain and feeding in the neonate with cleft-a 3 center study. Cleft Palate 7 1988;25:379-84.

9 Jensen B, Kreiborg S, Dahl E, Fogh-Anderson P. Cleft lip and palate in Denmark 1976-1981. Epidemiology, variability and early somatic development. Cleft Palate f 1988;25: $258-69$

10 Hunter W, Di J, Man D. The timing of height and weight deficits in twins discordant for cleft lip and/or palate. Cleft Palate f 1977;14:158. 